\title{
Control of CD4 gene expression: connecting signals to outcomes in $\mathrm{T}$ cell development
}

S.D. Sarafova and G. Siu

\author{
Department of Microbiology and the Integrated Program in Cellular, \\ Molecular and Biophysical Studies, Columbia University College of Physicians \\ and Surgeons, New York, NY, USA
}

Correspondence
G. Siu
Department of Microbiology
Columbia University College of
Physicians and Surgeons
701 West 168th Street
HHSC-610
New York, NY 10032
USA
Fax: +1-212-305-8013
E-mail: siu@ cusiu3.cpmc.columbia.edu

Presented at the I International Symposium on "Signal Transduction and Gene Expression in Cell Proliferation and Differentiation", São Paulo, SP, Brasil, August 31-September 2, 1998.

Research supported by the American Cancer Society (No. RPG-98-185-01-CIM) and National Institutes of $\mathrm{Health}$ of the United States (No. Al34925) to G. Siu.

Received November 26, 1998 Accepted March 9, 1999

\section{Abstract}

The control of CD4 gene expression is essential for proper T lymphocyte development. Signals transmitted from the T-cell antigen receptor (TCR) during the thymic selection processes are believed to be linked to the regulation of CD4 gene expression during specific stages of $\mathrm{T}$ cell development. Thus, a study of the factors that control CD4 gene expression may lead to further insight into the molecular mechanisms that drive thymic selection. In this review, we discuss the work conducted to date to identify and characterize the cis-acting transcriptional control elements in the CD4 locus and the DNA-binding factors that mediate their function. From these studies, it is becoming clear that the molecular mechanisms controlling CD4 gene expression are very complex and differ at each stage of development. Thus, the control of CD4 expression is subject to many different influences as the thymocyte develops.

\section{Introduction}

$\mathrm{T}$ cell development has long been the focus of intense study by both immunologists and developmental biologists. Like most cells, T cells mature from multipotent precursors which respond to environmental cues that affect their course of development (1). In the general developmental model, the precursor cell receives the environmental signal via a membrane-bound receptor. This receptor transmits the signal across the membrane to cytoplasmic signal transduction molecules, which in turn transmit the signal to the nucleus. Fate determination is mediated by the alteration of the program of gene expression in response to these signals. A multipo- tent precursor becomes a differentiated cell by inhibiting expression of genes that encode proteins important for maintaining the precursor state, and by initiating expression of genes that encode proteins required by the differentiated cell. The molecular mechanisms that mediate $T$ cell selection and development illustrate the level of complexity that can be accommodated by this seemingly simple paradigm.

Unlike B cells, which secrete immunoglobulin that can recognize soluble antigen, $T$ cells require presentation of the antigen by a specialized antigen-presenting cell (APC). In this process the APC engulfs the antigen, degrades it into small peptide fragments, and presents the peptides on its cell surface bound 
to a molecule encoded by the major histocompatibility complex (MHC; Figure 1). The $\mathrm{T}$-cell antigen receptor (TCR) recognizes a combination of both the antigenic peptide and the MHC molecule. Ligation of the TCR then leads to the activation and maturation of the $\mathrm{T}$ cell. There are two major classes of $\mathrm{T}$ cells: cytotoxic $T$ cells $\left(\mathrm{T}_{\mathrm{C}}\right)$ recognize and kill virally infected self cells, whereas helper $\mathrm{T}$ cells $\left(\mathrm{T}_{\mathrm{H}}\right)$ release cytokines that stimulate the other cell types in the immune system.

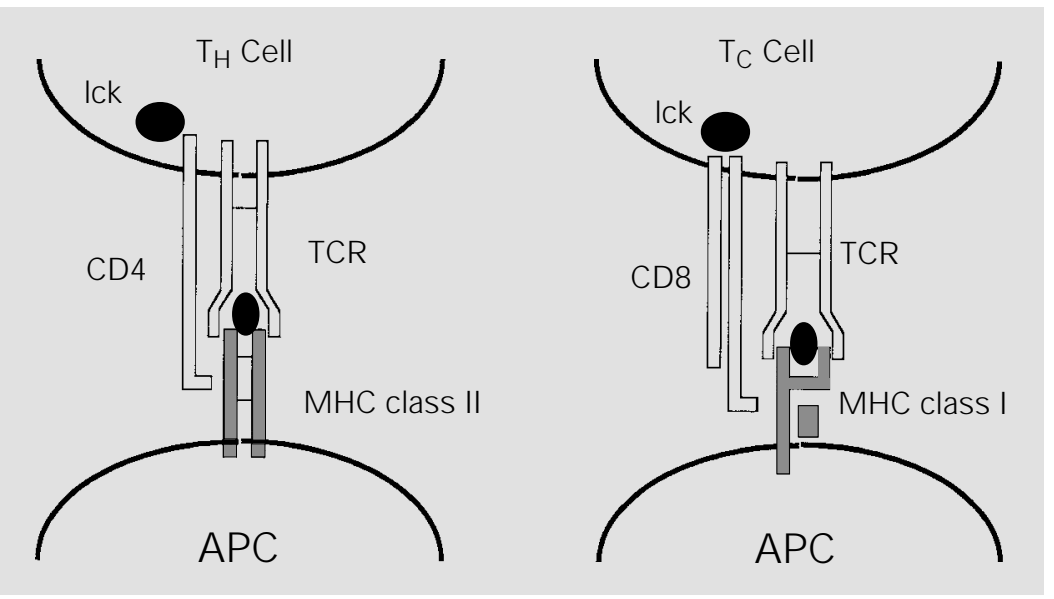

Figure 1 - Antigen recognition by helper $T\left(T_{H}\right)$ and cytotoxic $T\left(T_{C}\right)$ cells. Antigen-presenting cells (APC) are shown below. See text for details. TCR, T-cell antigen receptor.

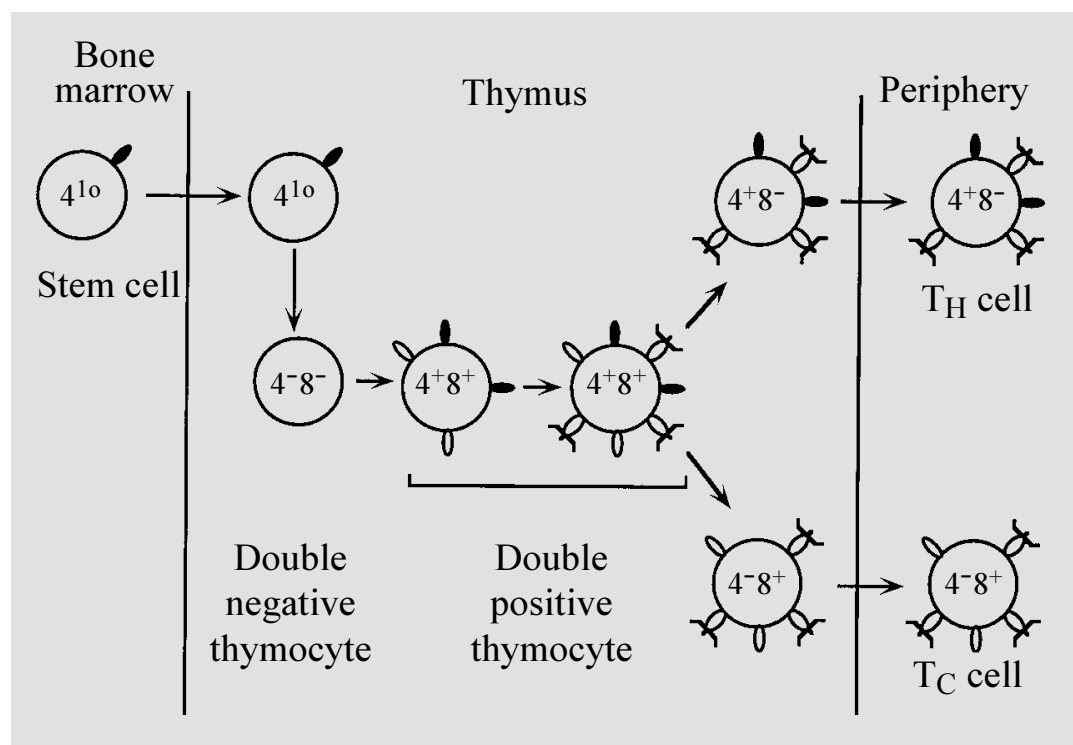

Figure 2 - T cell development in the thymus.
Most $\mathrm{T}_{\mathrm{C}}$ cells only recognize an antigen when it is bound to one type of MHC molecule, referred to as the MHC class I molecule. Conversely, most $\mathrm{T}_{\mathrm{H}}$ cells only recognize an antigen when it is bound to the second major class of MHC molecules, the class II molecule. This class specificity is enhanced by the T-cell-subclass-specific coreceptor molecules that bind to and distinguish between class I and class II molecules (Figure 1). The CD4 coreceptor molecule specifically recognizes MHC class II molecules, whereas CD8 recognizes MHC class I molecules. The interaction of the coreceptor with MHC serves both to increase the avidity of the T cell for the APC and to send additional stimulatory signals to the $T$ cell via an interaction with the tyrosine kinase lck.

Because $T$ cells need to recognize an antigen specifically as well as coordinate their function $\left(\mathrm{T}_{\mathrm{H}} v s \mathrm{~T}_{\mathrm{C}}\right)$ with their MHC specificity (class II $v s$ class I), the $\mathrm{T}$ cell development process is extremely complex. Despite their different roles in the immune response, $\mathrm{T}_{\mathrm{H}}$ and $\mathrm{T}_{\mathrm{C}}$ cells derive from a common precursor, achieving their mature functional capabilities and antigenic specificities during a complex developmental process that occurs primarily in the thymus (1; Figure 2). Immature $T$ cell precursors that first arrive in the thymus from the bone marrow express low levels of surface CD4; the expression of which is then downregulated, resulting in the CD4-CD8- or doublenegative (DN) thymocyte (2). These cells then express low levels of CD8, followed by high levels of both CD4 and CD8 and increasing levels of TCR. This population is referred to as the $\mathrm{CD}_{4}^{+} \mathrm{CD}^{+}$or doublepositive (DP) population $(1,3)$. Most of the TCR-mediated selection processes occur at this stage of development. $\mathrm{T}$ cells that can recognize $\mathrm{MHC}$ molecules are expanded in a process referred to as positive selection, and $T$ cells that are autoreactive are deleted during a process referred to as negative selection. Both of these events require the proper 
expression of CD4 and CD8 (4-7). The survivors downregulate either $\mathrm{CD} 4$ or $\mathrm{CD} 8$, leading to the mature single-positive (SP) populations. This downregulation is considered to be an important event in the final maturation of the $T$ cell in that surviving mature $\mathrm{T}$ cells expressing CD4 are restricted to $\mathrm{MHC}$ class II and are primarily $\mathrm{T}_{\mathrm{H}}$ cells, whereas those expressing CD8 are restricted to $\mathrm{MHC}$ class I and are primarily $\mathrm{T}_{\mathrm{C}}$ cells.

Numerous cell surface molecules are differentially expressed throughout the process of T-cell development and that is how the various developmental stages are defined. The question still remaining is what are the signaling events which lead to this differential expression and direct the developmental process. Many groups have taken several different approaches to characterize the signaling pathways that mediate T cell development. The first approach is to study the cell surface receptors that receive the external developmental signals and to characterize the signal transduction molecules with which they interact to transmit this signal through the cytoplasm (8). This approach has been extremely successful; with the advent of powerful mouse genetic tools such as transgenic animals and targeted disruptions, much has been learned about the signaling events that initiate the development process. However, it is difficult to link membrane-proximal signaling events with prospective targets in the nucleus. The second approach has been to identify genes that are expressed in cells representing specific $\mathrm{T}$ cell developmental stages using differential screening techniques (9). Although this can identify cell typespecific genes, the function of the corresponding gene product and its position in the signaling pathway are hard to determine. A third approach is to study the transcriptional control mechanisms of genes whose expression is controlled during the selection process. The signaling events that alter the expression of the gene during development are presumably linked to those signaling events that mediate the actual developmental process. Thus, determining how the transcription factors that control gene expression are induced to function by these developmental signals will hopefully provide important information on the pathway itself. The advantage of the last approach is that one is studying the target of the developmental signaling mechanism, which thus provides a molecular assay for membrane-proximal signaling events.

The control of CD4 gene expression provides an ideal system for studying the signaling events that drive $\mathrm{T}$ cell development, because the expression of CD4 changes with each of the major $T$ cell developmental stages in the thymus, and is critical for defining those stages. In addition, the downregulation of CD4 as the DP thymocyte matures into the CD8 SP T cell correlates to an important lineage decision. The two mature subclasses of $T$ cells differ significantly in their roles in the immune system and thus express different batteries of genes whose protein products mediate their different functions. For example, cytotoxic $T$ cells express granzyme $\mathrm{B}$ and perforin, both of which are critical for lysing target cells, consistent with their functional role in eliminating virally infected self cells $(10,11)$. Developing DP thymocytes that are fated to become $T_{C}$ cells must, therefore, both cease CD4 transcription and initiate transcription of these $\mathrm{T}_{\mathrm{C}}$-specific genes. Thus, the factors that mediate CD4 gene expression may be linked to the signaling processes that mediate $T_{C}$ fate determination during thymopoiesis, and an analysis of these factors will provide insight into the mechanisms that control these processes.

\section{Approaches for defining cis-acting transcriptional control elements}

\section{Transient transfection studies}

Although early work indicated that the control of CD4 expression occurs at many 
different levels, nuclear run-on data indicated that transcriptional control was the most critical mechanism (12). Initial approaches to studying $\mathrm{CD} 4$ gene expression were restricted to the standard techniques of using transient transfections of reporter gene plasmids into established cell lines. In this manner, a promoter and two transcription enhancers in the CD4 locus were identified and characterized (13-16) (Figure 3, and below). Nonetheless, it was clear from these experiments that critical transcriptional control elements had yet to be identified. First, despite the relative subclass specificity of the promoter, constructs that contained the promoter in combination with either enhancer functioned equally well when transfected into either CD4 SP or CD8 SP T cells, indicating that a negative regulatory element that repressed transcription in CD8 SP T cells was missing $(13,15,16)$. Second, the two enhancers were functionally indistinguishable; therefore, their individual roles in CD4 gene expression were unclear $(15,16)$. It became clear that the transient transfection system alone was not likely to be adequate for studying CD4 gene expression control.

\section{Identification of novel elements using transgenic mice}

The use of transgenic mice in characterizing transcriptional control elements in the
CD4 locus has proven to be extremely useful and provides distinct advantages over the traditional transient transfection approach. First, transient transfections utilize established cell lines. For the most part, these lines are transformed and thus the in vivo relevance of the results obtained is unclear. This is especially relevant for studies on $\mathrm{CD} 4$, as mature tumor $\mathrm{T}$ cell lines often downregulate CD4 expression when grown in culture. Second, cell lines used in transient transfection experiments are frozen at specific stages of development. By using established cell lines, one can thus study the elements that maintain or repress expression of CD4 at each particular stage; however, this approach is not useful to study those mechanisms that are involved in the transition between developmental stages.

It is possible to avoid these problems by using the transgenic approach (Figure 4). A cell-surface marker gene is put under the transcriptional control of different combinations of the CD4 transcriptional control elements. Transgenic mice are generated with these constructs, and the expression pattern of the marker gene on different $T$ cell populations is determined. Coexpression of the marker gene with endogenous CD4 indicates that all of the necessary transcriptional control elements are present on the test construct. By deleting different combinations of elements on the constructs and regenerating

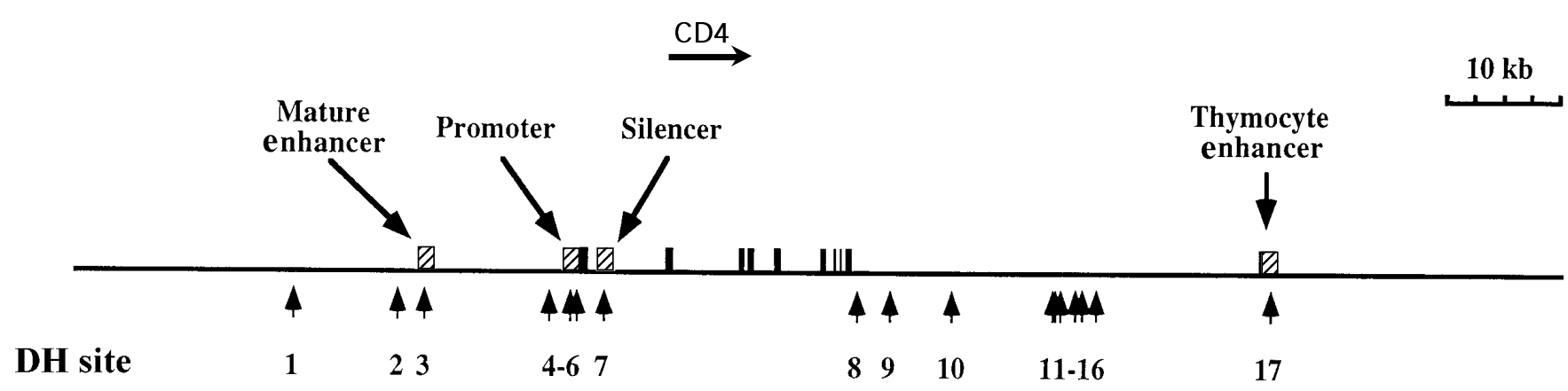

Figure 3 - The CD4 gene locus. A DNAse hypersensitivity $(\mathrm{DH})$ map of the CD4 gene locus is presented. The DH sites are indicated by numbered arrows. The direction of CD4 gene transcription is indicated by a horizontal arrow. The identified transcriptional control elements are represented by striped boxes. The CD4 gene exons are represented by black boxes. 
and analyzing the corresponding transgenic mice, it is possible to determine which of the elements are needed at each stage of $\mathrm{T}$ cell development. Similarly, specific factor-binding sites within individual elements can be tested for functional relevance. This approach enables the investigator to study the role of each transcriptional control element during the normal $\mathrm{T}$ cell development process in the animal itself, and has proven useful in iden- tifying the CD4 transcriptional control elements missing from the initial transient transfection experiments.

Several groups identified potential cisacting elements in the CD4 locus using DNAse hypersensitivity (DH) analyses $(12,15,17)$. These DH sites were assembled into reporter constructs. Transgenic mice were generated with these constructs and tested for marker gene expression on their

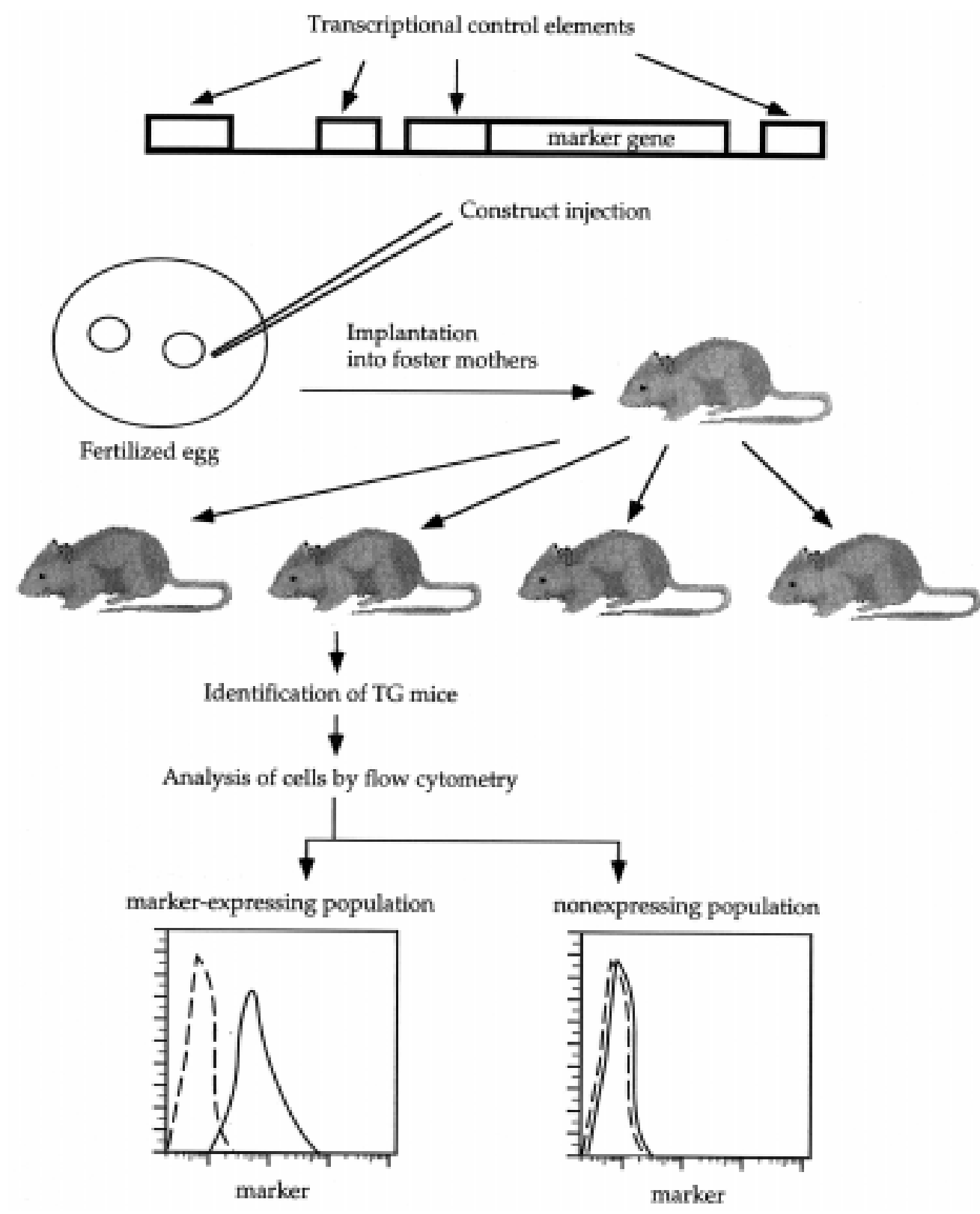

Figure 4 - A transgenic approach for studying control of gene expression. A construct with a marker gene (labeled marker) under the control of different combinations of CD4 control elements, represented by boxes, is introduced into fertilized eggs by microinjection and the eggs are implanted into pseudo-pregnant foster mothers. Transgenic progeny are identified and their peripheral lymphocytes analyzed by flow cytometry to determine expression patterns of the marker gene in different lymphocyte populations (CD4 SP populations are shown). The dashed line represents an isotype-matched control antibody staining. The solid line represents the marker gene antibody staining. 
lymphocyte populations (12,18; Adlam M and Siu G, unpublished results). Two additional transcriptional control elements were thus identified. First, a transcriptional silencer responsible for inhibiting CD4 gene expression both in DN thymocytes and mature CD8 SP T cells was identified in the first intron of the CD4 gene $(12,18)$. Second, a thymocyte enhancer that induces CD4 expression in DP thymocytes was identified (Adlam M and Siu G, unpublished results). Thus, transcriptional control elements that mediate full cell-type and developmentalstage-specific expression of CD4 have been identified. The remaining tasks were then to identify the factors that bind to each of these elements and mediate their function, and to determine how the function of these factors is affected during $\mathrm{T}$ cell development $(12,18,19)$.

\section{Defining transcriptional control elements in the CD4 locus}

\section{The promoter}

The CD4 promoter region was first defined by identifying the initiation point of transcription of the CD4 gene (13). Transient transfection experiments using reporter constructs containing $1.0 \mathrm{~kb}$ of flanking region $5^{\prime}$ to the initiation point of transcription indicated that this region indeed had promoter activity $(13,14)$. Although the promoter did not function without an enhancer in immature $T$ cells, its ability to function in mature $\mathrm{T}$ cells was unclear $(13,15)$. Transient transfections of enhancerless CD4 promoter reporter constructs into CD4 SP and CD8 SP T cell lymphomas indicated that an enhancer was also necessary for activity in these cells (15). However, transfection of similar constructs into antigen-specific $T$ cell clones, which resemble normal $\mathrm{T}$ cells more closely than tumors, indicated that the promoter alone was capable of functioning at high levels in these cells (13). T cell clones must be stimulated with antigen to allow them to be transfectable; this observation led to the hypothesis that the CD4 promoter is functional only in activated $\mathrm{T}$ cells (13). Transgenic mice with constructs that contain the promoter only expressed the marker gene in activated mature CD4 SP T cells, confirming the $\mathrm{T}$ cell clone transfection results and indicating that the control of CD4 expression differs between activated and resting $\mathrm{T}$ cells (20). Transient transfection data also demonstrated that promoter constructs transfected into CD4 SP $\mathrm{T}_{\mathrm{H}}$ clones yielded 5-10 X higher activity than when transfected into CD8 SP $\mathrm{T}_{\mathrm{C}}$ clones, indicating a relative subclass specificity for promoter function (13). Initial transgenic experiments that demonstrated the lack of specificity of promoter function utilized constructs that contained both the promoter and the mature enhancer; thus, this lack of specificity was most likely the result of the enhancer overriding promoter specificity $(12,18)$.

Transient transfection experiments with the promoter indicated that the murine CD4 promoter can be deleted to a fragment that contains only $101 \mathrm{bp}$ of the 5 ' flanking region and still maintain full activity (13). Further deletions crippled promoter function, indicating that the critical factor-binding sites in the CD4 promoter were within this 101-bp fragment. Four functional regions were defined using a linker-scanning mutational approach. Each of these sites, when mutated alone, results in significant reduction of CD4 promoter activity, indicating that no one promoter-binding factor is mediating function alone and that each is required to form the initiation complex (Figure 5) (21). Using biochemical and transient transfection approaches, it was determined that at least five different factors bound to these four regions: c-Myb (13,22), MAZ (21), Elf-1 (23), and two factors that have yet to be characterized. The hematopoietic transcription factor c-Myb binds to two recognition sites in the promoter, referred to collectively as P1, and can 
transactivate the promoter in transfection experiments $(13,22)$. These data indicated that $\mathrm{c}-\mathrm{Myb}$ was acting as a positive transcriptional regulator for the CD4 gene; indeed, the CD4 gene was one of the first natural targets of the c-Myb protein identified. The second site, $\mathrm{P} 2$, is directly adjacent to the c-Myb recognition sites and contains three overlapping recognition sites for the transcription factor MAZ. Although at least two of the three recognition sites must be intact for full promoter function, only one MAZ-P2 complex can be identified biochemically, indicating that there may be some flexibility in MAZ recognition (21). The P4 site is located adjacent to the first initiation point of transcription of the CD4 gene (23). Biochemical studies indicate that the Elf-1 transcription factor binds to $\mathrm{P} 4$ and helps mediate promoter function; interestingly, a second factor also binds to the Elf-1 recognition site with identical sequence specificity (23). The identity of this second factor and its possible role in CD4 promoter function are unknown. Similarly, the factor(s) that bind(s) to P3 remain(s) uncharacterized. Interestingly, although there is relative subclass specificity for promoter function, none of the promoter-binding factors are expressed in a subclass-specific manner. As it will become apparent, the motif of functional specificity and biochemical ubiquity will recur in the other transcriptional control elements in the CD4 locus.

\section{The mature $\mathbf{T}$ cell enhancer}

The CD4 mature T cell enhancer (previously referred to as the 'proximal enhancer') was originally identified as a DH site in the CD4 locus (15). In transient transfection experiments, the CD4 mature T cell enhancer functions in a T-cell- but not subclass-specific manner (15). Consistent with this, transgenic mice with constructs that contain this enhancer only express the marker gene in both CD4 and CD8 SP splenocytes (12,18,24-
26). In contrast to the transient transfection experiments, however, the $\mathrm{CD} 4^{+} \mathrm{CD}^{+}$thymocytes in these transgenic mice do not express the marker, indicating that additional cis-acting sequences are necessary to induce CD4 expression in the immature DP population (24-26). Interestingly, the CD4 SP thymocyte population in these transgenic mice is divided into two populations: one that expresses the transgenic marker and one that does not (24-26; Figures 5, 6 and 7). To characterize these populations Adlam and colleagues (24) investigated further the exact developmental stages of these populations as determined by the expression pattern of the heat stable antigen (HSA), CD69, and MHC class I molecules on these cells. HSA is a marker expressed on immature thymocytes and is downregulated in mature T cells, while MHC class I is expressed at low levels in thymocytes and is induced in mature T cells. CD69 is proposed to be a marker for the CD4 SP thymocytes undergoing the TCR-mediated repertoire selection process (27). As can be seen in Figure 6, the marker-negative CD4 SP population ex-

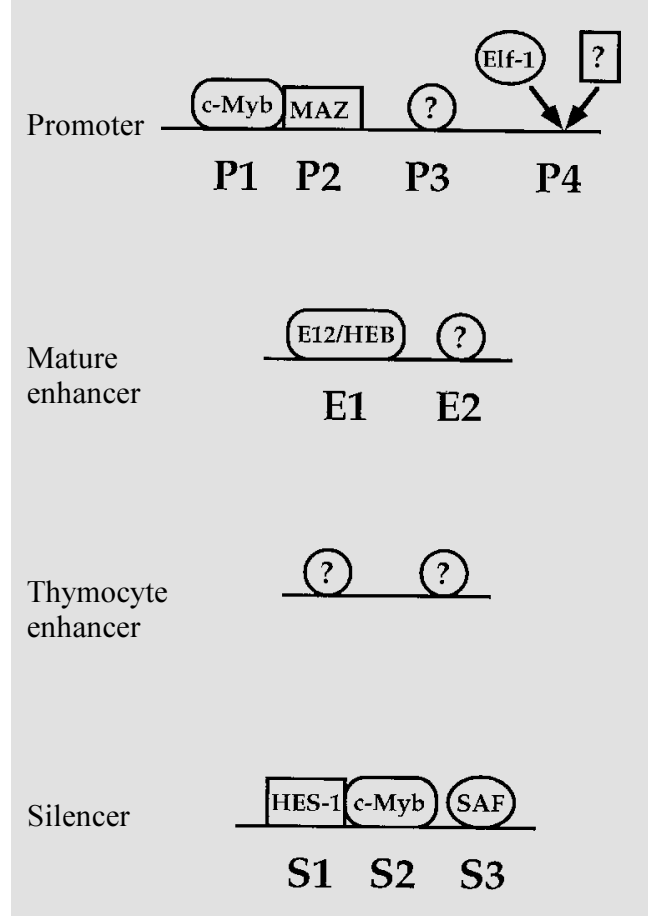

Figure 5 - Schematic representation of the transcription control elements of CD4 and their factors. The binding sites within a control element are designated by a letter and a number: $\mathrm{P}$ for promoter sites, $\mathrm{E}$ for mature enhancer sites, and $\mathrm{S}$ for silencer sites. Interacting factors are indicated above their binding sites. A question mark is used when the factor is unknown. Data were from the following references: for the promoter $(13,21,23)$, for the mature enhancer (28; Adlam M, Allen RD \& Siu G, unpublished data), and for the silencer $(32,34)$. 
pressed high levels of HSA and CD69 and low levels of MHC class I, whereas the marker-positive CD4 SP thymocytes express low levels of HSA and high levels of MHC class I (24). These data indicate that the marker-negative CD4 SP thymocytes are undergoing the selection process, whereas the marker-positive CD4 SP thymocytes have survived the process and are ready to emigrate from the thymus. Thus, this enhancer is induced to function only in mature $T$ cells, and its induction of function may be directly linked to the signals that mediate the repertoire selection process (24). Because of the pattern of function, we propose that this enhancer be referred to as the CD4 locus mature enhancer.

Sawada and Littman $(15,28)$ characterized a minimal 339-bp restriction enzyme fragment that was required for full enhancer function in transient transfection assays. There are two factor-binding sites within the core enhancer region. The first site (referred to here as the E1 site) is recognized by a heterodimer of two factors from the basichelix-loop-helix transcription factor family: HEB and E12, the latter a product of the E2A gene $(29,30)$. The factor binding to the second site (E2) is believed to be a truncated form of the c-Myb transcription factor (Adlam M, Allen RD and Siu G, unpublished data). In contrast to the transient transfection experiments, however, transgenic experiments indicated that enhancers containing site-specific mutations in the E1 site are completely functional, whereas enhancers containing mutations in the E2 site are nonfunctional, indicating that it is the truncated c-Myb factor and not the E12/HEB heterodimer that is important for enhancer function (Adlam M, Allen RD and Siu G, unpublished results). However, although the enhancer functions in a mature $T$ cell-specific manner, the truncated c-Myb factor that binds to it and medi-

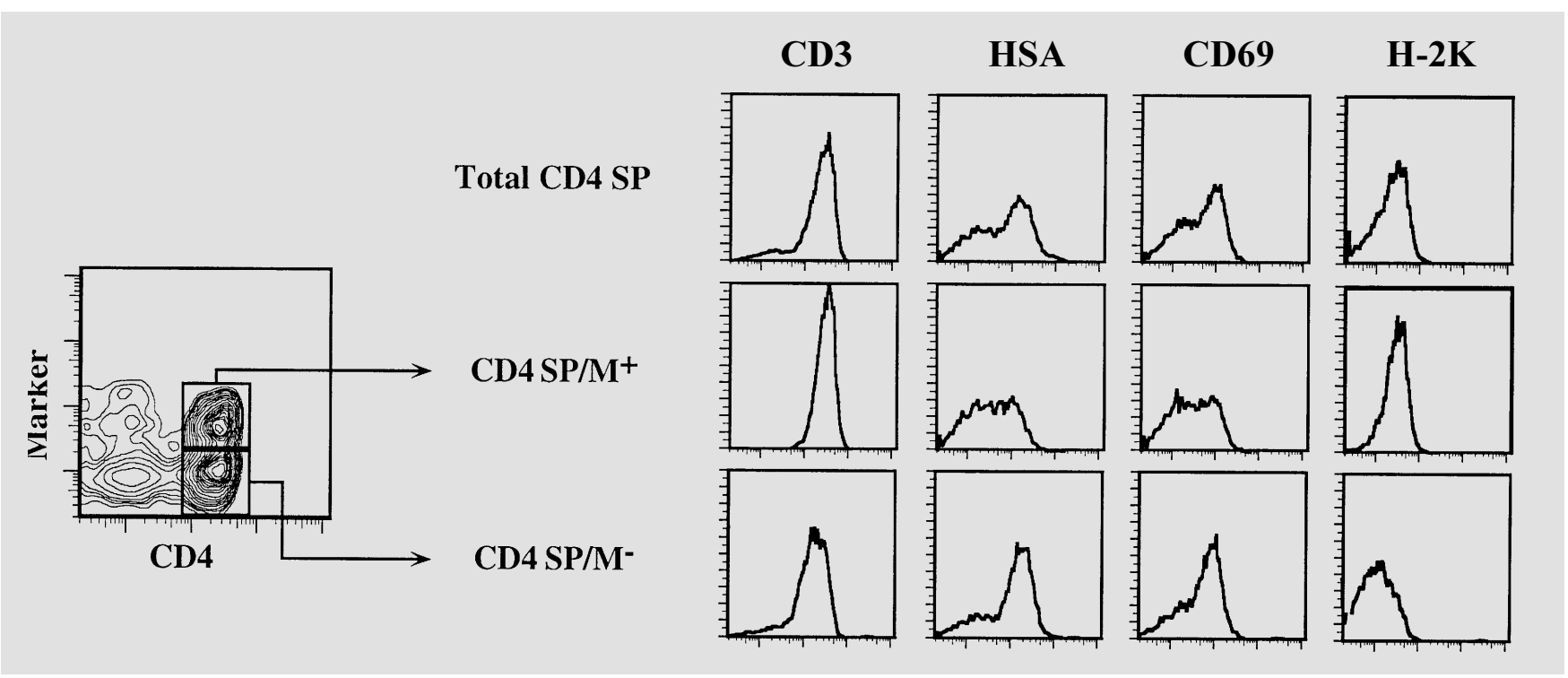

Figure 6 - Representative analysis of pTG mice. Thymocytes from mice transgenic for a construct, containing the CD4 promoter and the CD4 mature enhancer, were stained with antibodies to the CD4, CD8 and TG markers, and the cell-surface markers indicated and analyzed by flow cytometry. CD8 ${ }^{+}$ cells were eliminated from the analysis and the remaining cells were plotted in two-color flow cytometric plots with CD4 expression on the x-axis and TG marker expression on the $y$-axis (left panel). The marker-positive (CD4 SP/M+) and marker-negative (CD4 SP/M-) CD4 SP thymocytes were gated on and analyzed for expression of CD3, heat stable antigen (HSA), CD69, and H-2K and compared to staining in the complete CD4 SP population (CD4 SP). The CD4 SP/M- population stains $\mathrm{HSA}^{+}, \mathrm{CD}^{+} 9^{+}$, and $\mathrm{H}-2 \mathrm{~K}^{\mathrm{l}}$, consistent with a CD4 SP thymocyte undergoing positive selection. In contrast, the CD4 $\mathrm{SP} / \mathrm{M}^{+}$population is $\mathrm{HSA}{ }^{\mathrm{lo}}, \mathrm{CD} 69 \mathrm{lo}$, and $\mathrm{H}-2 \mathrm{~K}^{\text {hi }}$, consistent with a CD4 SP thymocyte that has successfully survived positive selection. Data taken from Adlam et al. (24); see references therein. 
ates its function is expressed in all lymphocytes; thus the specificity of function of these factors is not due to the induction of their expression.

\section{The silencer}

Despite the identification of the mature enhancer and the promoter, transient transfection experiments were unable to identify the cis-acting elements that would convey full subclass specificity at all stages of $T$ cell development. Using transgenic approaches, we and others identified a negative regulatory region in the first intron of the CD4 gene that, when included in transgenic constructs, repressed enhancer function in $\mathrm{CD}^{-}$cells and thus conveyed full subclass-specific expression of the marker gene $(12,18)$. This element functioned in a position- and orientation-independent manner and could repress transcription from heterologous promoters and enhancers, thus fulfilling the requirements of a true transcriptional silencer $(12,18)$. The core 434-bp silencer region contains three factor-binding sites referred to as $\mathrm{S} 1, \mathrm{~S} 2$, and $\mathrm{S} 3$ that are bound by factors expressed in all $\mathrm{T}$ cells (31). By deleting different combinations of sites in the silencer and testing each mutant silencer in transgenic assays, Duncan and colleagues (31) determined that all three factor-binding sites are important for silencer function. However, there is significant functional redundancy: in order to abrogate silencer function, the central factor-binding site must be deleted in combination with either one of the two flanking sites. Deletion of any one of the three sites alone, or deletion of the two flanking sites does not affect silencer function (Figure 8). Thus, despite the redundancy, all three factor-binding sites are important for full silencer function.

Three silencer-binding factors have been identified and, true to form, none are expressed in a subclass-specific manner. Using a variety of biochemical and genetic ap- proaches, Kim and Siu (32) determined that the basic-helix-loop-helix protein HES-1 binds to $\mathrm{S} 1$ and helps mediate silencer function. These observations are especially interesting in that HES-1 is a target of the lin 12 / Notch signaling pathway, which is an important developmental pathway and has been implicated in the control of $\mathrm{T}$ cell fate decisions (33). However, its role in the specification of CD8 SP versus CD4 SP T cell development is unclear, as we have been unable to detect $T$ cell subclass-specific differences in HES-1 expression or modification (Kim $\mathrm{H}$ and Siu G, unpublished results). The S2

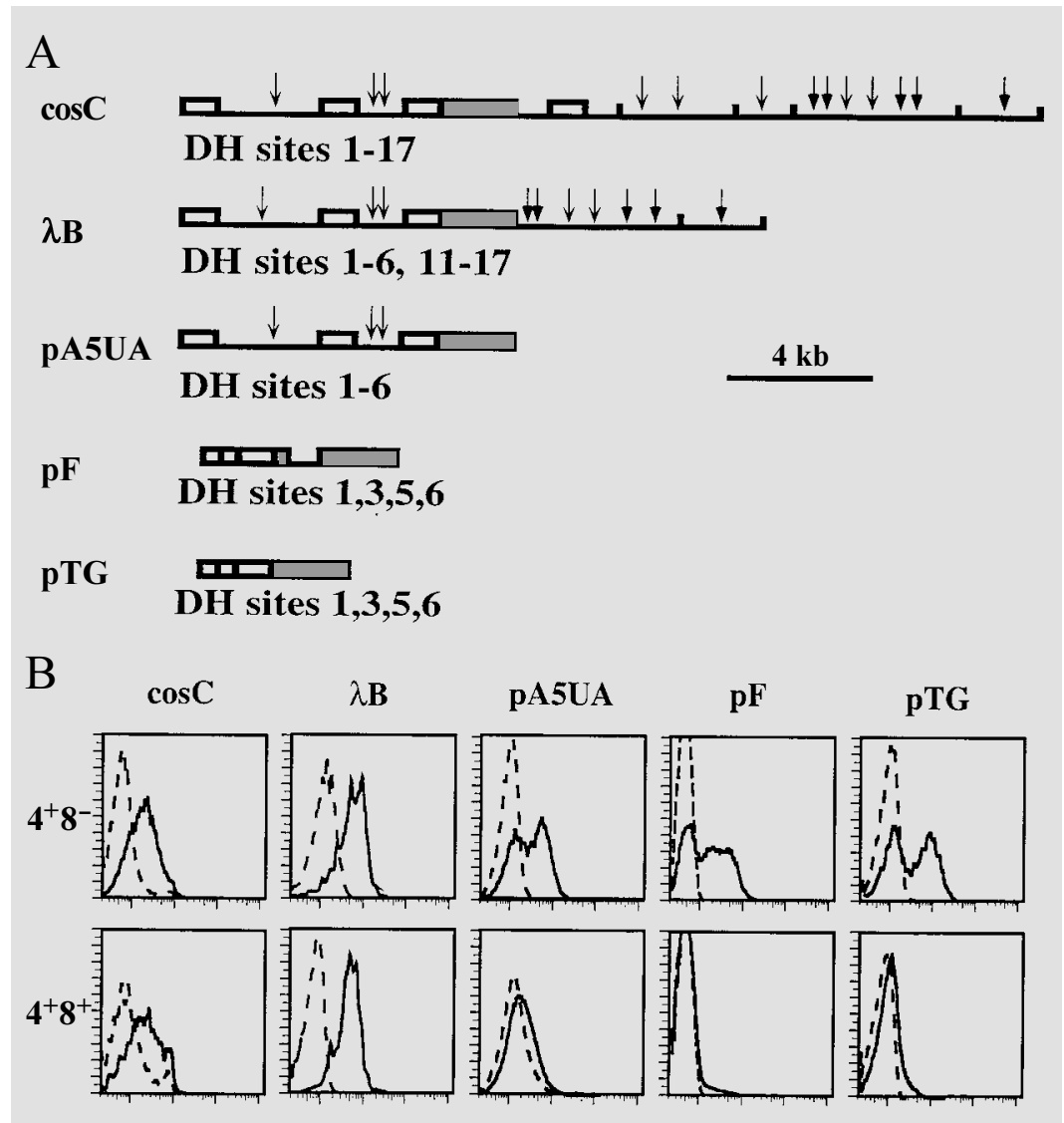

Figure 7 - The transgenic constructs used to identify the thymocyte enhancer. A, Transgenic constructs. Gray boxes - marker gene; open boxes - transcriptional control elements; arrows - additional DNAse hypersensitivity (DH) sites present, as identified originally in Figure 3. B, Histograms depicting marker expression in CD4 SP and double-positive (DP) thymocytes, using the constructs from A. Solid line - marker expression; dashed line - isotype-matched control. The constructs which contain $\mathrm{DH}$ sites $11-17(\cos \mathrm{C}$ and $\lambda \mathrm{B})$ have clear marker expression in the DP thymocytes, while the constructs that do not contain DH sites 11-17 (pA5UA, pF and pTG) have no expression in the DP thymocytes and only a portion of the CD4 SP thymocytes express the marker gene. Data are from Adlam et al. (24). 
region has a consensus $\mathrm{c}-\mathrm{Myb}$ recognition site; indeed, alignments of the S2 sequence with the P1 region of the promoter show significant sequence similarity. Using biochemical approaches, Adlam and colleagues determined that c-Myb is in fact binding to S2 specifically, and is a component of the major S2-binding complex (Adlam M, Allen RD and Siu G, unpublished results). Interestingly, c-Myb was determined to bind directly to HES-1 in vivo, indicating that the two factors may form a functional active silencer-binding heterodimer (Kim HK, Allen RD and Siu G, unpublished results). Demonstrating a direct role for c-Myb in the control of CD4 gene expression has been difficult, since c-Myb binds both to positive and negative regulatory elements in the CD4 locus, which complicates reporter assay readouts. To make matters worse, functional assays for the silencer are limited predominantly to genetically manipulated mice. An analysis of the role of c-Myb in lymphocyte development using targeted disruption indicates that $\mathrm{T}$ cell progenitors are blocked at an early DN stage, precluding the use of conventional targeted disruptions in studying the role of cMyb either in silencer function or in later stages of $\mathrm{T}$ cell development (33a). However, conditional targeted disruptions of the c-Myb gene are currently being generated which will provide much useful information on the role of c-Myb in these processes.

As defined by DNAse footprinting, the S3 site of the silencer consists of a large 56bp region (31). Using yeast one-hybrid screening techniques, Kim and Siu (34) identified a novel transcription factor, referred to as Silencer Associated Factor (SAF), that binds within this region. This factor is a 14$\mathrm{kDa}$ protein with discrete functional domains, including a helix-turn-helix DNA binding
Figure 8 - Functional redundancy of the silencer binding sites. FACS analysis of marker expression in peripheral lymphocytes is shown for CD4 SP and CD8 SP cells. The constructs contain the marker gene driven by the CD4 promoter and enhancer and either the full-length silencer (pTGSil), no silencer (pTG), or silencers with different sites deleted as indicated above each plot. The solid line represents the marker stain; the dashed line represents the isotype-matched control stain. A marker-positive population in the CD8 SP cells indicates a break in silencing. No break of silencing is observed in the CD8 SP population in the single-site deletion silencer mutants $(\Delta 1, \Delta 2$ and $\Delta 3)$. The lower panels show the double and triple deletions of the binding sites; all break silencing in the CD8 SP population with the exception of $\Delta \mathbf{1} / 3$. Data are from Duncan et al. (31).
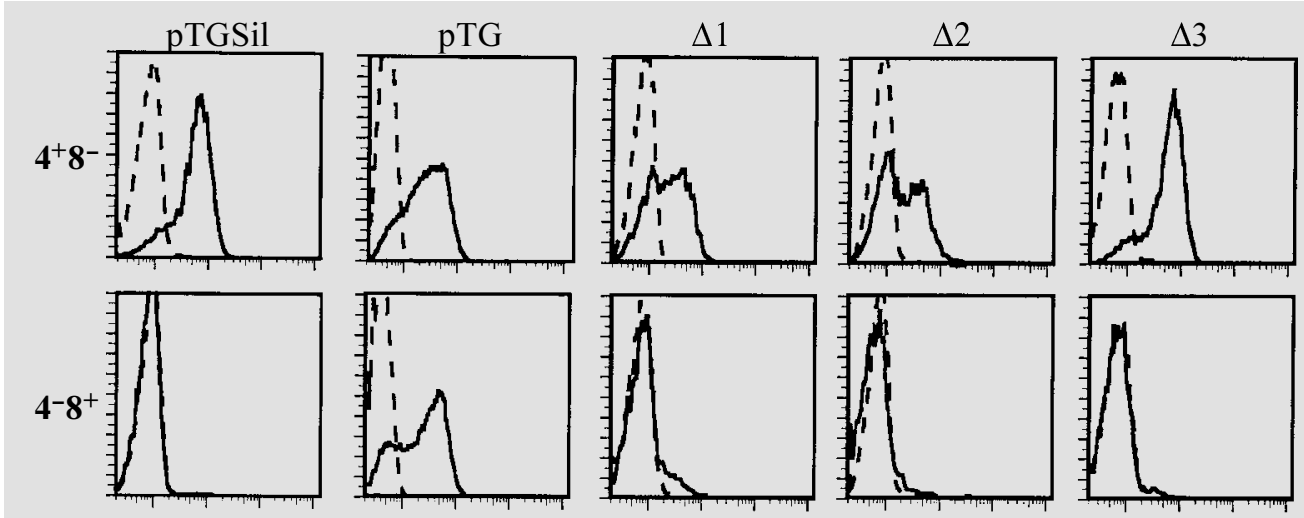

$\Delta 1 / 2$
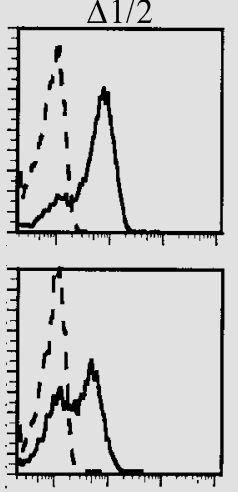

$\Delta 1 / 3$
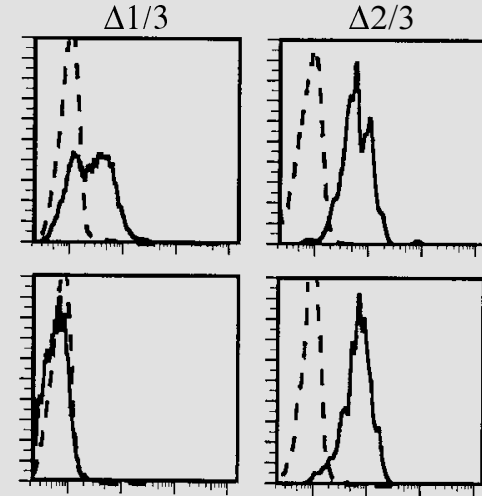

$\Delta 1 / 2 / 3$

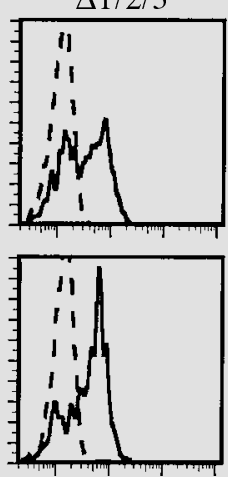


domain that shares significant structural similarity with the homeodomain class of transcriptional regulators. In combination with the S2 deletion, site-specific mutations in the SAF-binding site within the S3 region leads to loss of silencer function, supporting the hypothesis that SAF is important in silencer function. SAF is expressed in a wide variety of cell types, including all subsets of T cells. However, immunofluorescence studies indicate that in $\mathrm{T}$ cells in which the endogenous silencer is nonfunctional, such as $\mathrm{CD} 4 \mathrm{SP}$ and $\mathrm{CD}^{+} \mathrm{CD}^{+}$cells, SAF is present primarily in the cytoplasm, whereas in $T$ cells in which the silencer is functional, such as CD8 SP and CD4-CD8- cells, SAF is present primarily in the nucleus. Thus, SAF localizes to specific subcellular compartments during T cell development, depending on the specificity of endogenous silencer function. Thus, SAF may play an important role in mediating the specificity of function of the CD4 silencer during T cell development. Further studies are in progress to determine more precisely the role of SAF in both CD4 silencer function and $\mathrm{T}$ cell development.

One interesting feature unique to the CD4 silencer is the functional redundancy of its factor-binding sites. In this regard, the CD4 silencer is similar to the yeast mating-type silencer HMR-E. This functional redundancy may be playing an important role in the coupling of silencer function with other developmental processes. For example, the three factors that bind to the yeast mating-type silencer (35) are important not only in transcriptional repression but also in transcriptional activation, and can thus coordinate silencer function with the expression of other genes. In addition, several of the HMR-E-binding factors are important in the initiation of DNA replication and telomere function. Because of the multiple roles of these factors, it is possible to link different biological processes with transcriptional silencing. For example, it is critical for the yeast cell to inherit the silenced state around the mating-type locus during mitosis, and thus the requirement of the silencer-binding factors both for silencing and replication insures that these two processes are functionally linked. All three factors that bind to the CD4 silencer have also been shown to play multiple roles in mammalian cell development and function (36-38; Kim WWS and Siu G, unpublished data). Thus, functional redundancy could provide significant flexibility in the control of CD4 silencer function at different $\mathrm{T}$ developmental and functional stages.

\section{The thymocyte enhancer}

One of the more surprising results to come out of the transgenic analyses was the identification of multiple enhancers in the CD4 locus that function at discrete stages of T cell development. As discussed above, the characterization of the mature CD4 enhancer led to the hypothesis that a second enhancer in the CD4 locus was required for induction of CD4 expression during the early stages of $\mathrm{T}$ cell development. Using a transgenic approach, Adlam and coworkers (24) predicted the existence of a thymocyte enhancer in a cluster of DH sites located in the 3' flanking region of the CD4 gene (Figures 3 and 7). Mice transgenic with constructs that do not contain the silencer but contain DH sites 1117 expressed the marker gene in DP thymocytes as well as B cells and macrophages, whereas those constructs without DH11-17 only express the marker in mature $\mathrm{T}$ cells (Figure 7 and $(12,24)$ ). In addition, transgenic mice with constructs that contain both the silencer and DH1 1-17 express the marker only in $\mathrm{CD}^{+}$thymocytes (12). Taken together, these data indicate that there is an additional enhancer in the CD4 locus within DH11-17 that can induce CD4 gene expression in a wide variety of different hematopoietic cell types; its function is restricted to 
$\mathrm{CD}^{+}$cells in vivo due to the action of the silencer. Preliminary transgenic data using additional constructs indicate that a thymocyte enhancer is indeed located in this region (Adlam M and Siu G, unpublished results). Because of the unique developmental specificity of this enhancer, it will be particularly interesting to study the factors that bind to the DP enhancer and mediate its function.

\section{Other elements}

Using transient transfection studies, Wurster and colleagues (16) identified a second enhancer in the CD4 locus, located 25 $\mathrm{kb} 5$ ' of the initiation point of transcription of the CD4 gene. Functionally, this enhancer overlapped completely with the mature enhancer and the promoter, and thus its role in the control of CD4 gene expression was unclear. Triebel and colleagues (39) reported that the LAG-3 gene was located upstream of the CD4 gene in the genome, and that this enhancer is located $1.5 \mathrm{~kb} \mathrm{5}$ ' of the initiation point of transcription of the LAG-3 gene, leading to the hypothesis that this enhancer is actually an enhancer for the LAG-3 gene instead of the CD4 gene. However, subsequent studies indicated that this enhancer cannot enhance the LAG-3 promoter in transient transfection analyses. In addition, transgenic studies demonstrated that although this enhancer is capable of enhancing transcription from the CD4 promoter in transient transfection analyses (16), it cannot do so in transgenic assays (Adlam M, Allen RD and Siu $\mathrm{G}$, unpublished data), thus making it unlikely that this enhancer plays a role in CD4 gene expression. The role of this enhancer in the transcriptional control of any gene remains unknown.

\section{Controlling the specificity of CD4 gene expression}

Although the identification of the cis- acting transcriptional control elements that mediate specificity of CD4 expression has been largely successful, the manner in which the different factors mediate the specificity and function of each element remains unclear. In mediating expression, the factors that bind to these elements must perform two functions: they must either stimulate or inhibit the transcriptional machinery (the mechanism of action), and they must do so in a subclass-specific manner (the specificity of action). These two functions may be completely distinct from each other, requiring different sets of factors, or there may be significant functional overlap. Nonetheless, in constructing models for the role of the factors that bind to the CD4 transcriptional control elements in mediating gene expression, it is useful to consider these concepts separately.

\section{Mediating specificity: post-translational modification of transcription factors}

Although the control of specificity of element function remains obscure, it is clear that function is not mediated by the specific expression of the element-binding factors. For example, the CD4 silencer is the critical element that controls the specificity of CD4 expression in mature $T$ cells, and yet all of the characterized silencer-binding factors are expressed in both CD4 and CD8 SP T cells (31,32,34; Adlam M, Allen RD and Siu G, unpublished results). At first, these observations appear contradictory in that a combination of DNA-binding factors expressed in a wide variety of different tissues mediates $T$ cell subclass-specific function of a transcriptional control element. However, these data may actually be indicating a possible mechanism for the control of specificity of CD4 gene expression. This is due to the timing of transmission of the initial differentiation signal from the surface of the thymocyte during the selection process (40). Presumably, the signal to differentiate to a mature $\mathrm{T}$ cell 
occurs during the $\mathrm{CD} 4^{+} \mathrm{CD} 8^{+}$thymocyte stage. Thus, the components of this signal transduction pathway are likely to be expressed in DP. This would predict that the initial nucleus-bound signal to start the program of differentiation to a CD8 SP $\mathrm{T}_{\mathrm{C}}$ cell, for example, is transmitted by the modification of existing factors by one or more mechanisms, schematically depicted in Figure 9. It is possible that the CD4 transcriptional control elements are direct targets of the initial TCR-mediated selection signal from the surface of the DP thymocyte; should this be the case, the factors that bind to them may be induced to function in DP thymocytes in response to these signals. One particulary striking observation consistent with this hypothesis is the subclass-specific localization of SAF in T cells; SAF is present largely in the nucleus in CD4- $\mathrm{T}$ cells, where presumably it has access to its cognate recognition site in the CD4 silencer. Alternatively, SAF is present largely in the cytoplasm of $\mathrm{CD} 4^{+} \mathrm{T}$ cells, and thus does not have access to the silencer and cannot mediate its function (Figure 9B). It is possible that signaling via the T-cell antigen receptor during selection induces the translocation of SAF into the nucleus, thus initiating a cascade of developmental events that lead to the specification of the CD8 SP $\mathrm{T}_{\mathrm{C}}$ lineage, including the induction of $\mathrm{CD} 4$ silencer function.

\section{Mediating specificity: subclass-specific expression and function}

It is also still possible that subclass-specific factors are mediating CD4 cell-typespecific expression. Subclass-specific coactivators may mediate interaction of the constitutively expressed DNA-binding factors with the basal transcriptional machinery. For example, the Oct1 transcription factor conveys B-cell specificity to the immunoglobulin promoter and is required for its function. Oct1 itself is expressed ubiquitously; however, OCA-B, a non-DNA-binding B cell- specific coactivator protein, is required to link Octl function with the basal transcription machinery and induce promoter function (41). It is possible that the factors that mediate CD4 element function also interact with $\mathrm{T}$ cell subclass-specific coactivators that convey the appropriate subclass-specificity. CD8 T cell-specific coactivators may interact with the more ubiquitously expressed silencer-binding factors HES-1, c-Myb, and SAF to link their function to the basal transcription machinery; alternatively, CD4-specific coactivators may interact with the promoter-binding factors to mediate promoter function in activated $\mathrm{T}_{\mathrm{H}}$ cells (Figure 9C). This model predicts, however, that the element-binding factors are not direct targets of the selection signal in the DP thymocytes and that the factors that control subclassspecific coactivator expression would be more likely candidates.

Specificity may also be mediated by combinations of different factors in different cell types. For example, the genes encoded in the yeast mating-type locus can repress or activate transcription in different cell types depending on the juxtaposition of the recognition site of one factor with that of other transcription factors (42). The $\alpha 1$ homeodomain transcription factor can repress the transcription of haploid-specific genes by binding to operator sequences in promoters in conjunction with the a1 homeodomain transcription factor (43). However, $\alpha 1$ can also activate the transcription of $\alpha$-specific genes by binding to different promoter sites in conjunction with the MCM1 transcription factor (44-47). The two different $\alpha 1$-containing heterodimers differ both in DNA binding affinity and in sequence specificity (48-50). Thus, in this system, arrangements of specific DNA sequences act as nucleation sites for the assembly of groups of regulatory proteins on DNA, and it is the assembly of proteins as a whole as opposed to the presence of a particular protein that determines the specificity of expression of the target 
gene. This model predicts that specificity of element function is not conveyed by specific expression of nuclear factors but rather by the subclass-specific interactions of different combinations of factors (Figure 9D).

\section{Mediating function}

The manner in which the different nuclear factors mediate the function of the CD4

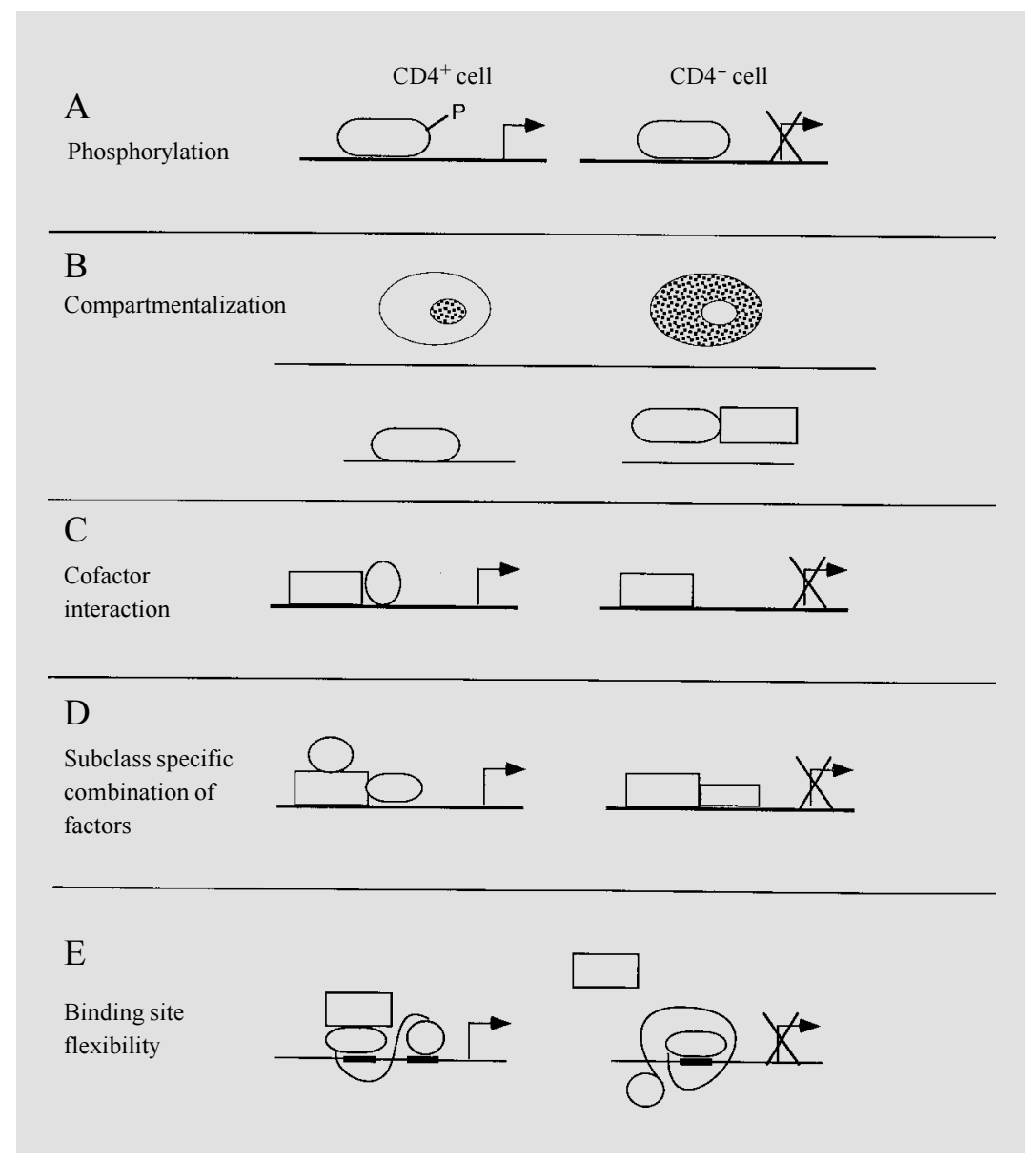

Figure 9 - Possible models for subclass specific regulation using ubiquitous or nonsubclass specific factors. For simplicity, only one of the numerous possibilities is shown in each case. A, Phosphorylation determines the presence or absence of activity of the factor. B, Sequestration of the factor away from the nucleus (top) or away from its binding site (bottom) prevents it from participation in the element regulation. $\mathrm{C}$, Association with yet unidentified subclass-specific cofactor(s) determine(s) the functionality of the element. D, Different combinations of cofactors occur at different stages of $\mathrm{T}$ cell development to positively or negatively regulate an element's function. $\mathrm{E}$, The same factor binds to different configurations of its binding site and adopts different conformations, which allow interactions with different cofactors. Arrow: transcription; crossed-out arrow: lack of transcription; ovals and boxes: different transcription factors except in top part of $B$, where ovals represent a cell and its nucleus. transcriptional control elements is conceptually more straightforward. The enhancerbinding factor E12/HEB is a transcriptional regulator that is known to induce transcription. Indeed, members of this family were first identified by characterizing factors that bound to the immunoglobulin heavy-chain gene enhancer (51). Similarly, the promoterbinding factors c-Myb, MAZ, and Elf- 1 were all initially characterized as promoter-binding factors that induced transcription $(36,52,53)$. The mechanism for the silencerbinding factors, however, is still unclear. HES-1 has been characterized as a transcriptional repressor $(37,54)$. However, as discussed above, c-Myb has been previously characterized as a positive transcriptional regulator, and thus its potential role in silencer function is unclear. It is possible that different contexts of the c-Myb binding site allow it to function either as a transcriptional activator or a repressor depending on its specific interactions with the other silencing proteins.

Interestingly, structural work by Aggarwal and colleagues (55) has led them to propose a model for different effects of a transcription factor on different transcriptional control elements. The transcription factor Pit-1 binding to DNA as a homodimer recognizes sites on perpendicular surfaces of the DNA helix. The spacing distance between the two sites is variable, depending on the promoter; because of this, Pit-1 is configured differently on different DNA recognition sites. This flexibility may enhance the range of cooperative interactions between Pit-1 and coactivators; therefore, the same factor may be used in different contexts on different DNA elements to achieve cell type-specific actions. Binding site flexibility could also be a mechanism for specificity of function of cMyb at the CD4 promoter and silencer (Figure 9E). The promoter has two c-Myb recognition sites, whereas the silencer has one; it is possible that binding to a single site in the silencer gives c-Myb a different conforma- 
tion than binding to a double site in the promoter. In one configuration, c-Myb acts as a transcriptional activator on the promoter, whereas in the second configuration, it acts as a repressing element within the silencer. Thus, the same factor can be used either as an inducer or a repressor of transcription, depending on its secondary structure, which in turn depends on the configuration of its binding site.

\section{Wheels within wheels: complexities of CD4 gene expression control}

In 1550, the astronomer Giovanni de Dondi of Padua built a complex model to describe the orbital paths of the different planets. At the time, scientists believed the earth to be the center of the universe; because their point of perspective was incorrect, their plotted paths for each planet was complex and different. The sun and the moon both have circular orbits, of course, but each of the planetary orbits have complicated epicycles - that is, the rolling of wheels within wheels - that were originally described mathematically by Ptolemy. Beautiful as it is, de Dondi's model has one major flaw. As stated by Jacob Bronowski in his book on science and humanism, The Ascent of Man: "...what is wrong with it? One thing only: that there are seven dials for the heavens - and the heavens must have one machinery, not seven (56)."

Classical astronomy had Nicolaus Copernicus to clarify matters and present a much simpler model for the galaxy in 1543 (seven years earlier - it is a pity that de Dondi did not conduct a more thorough literature search!). Unfortunately, studies on the specificity of control of CD4 gene expression indeed, in the specificity of signal transduction in general - are unlikely to be as lucky. However, like the pre-Copernican astronomers, we believe that we have at least identified the important players. There are at least four elements functioning in different com- binations at different stages that mediate CD4 gene expression during development (Figures 10 and 11). At the early stem cell stage, the thymocyte enhancer induces low levels of expression of CD4. The stem cells that further develop into B cells, macrophages, and other hematopoietic cells initiate silencer function and thus repress CD4 expression throughout the remaining life of the cell. However, commitment to the $\mathrm{T}$ cell lineage leads to a complex program of CD4 gene expression that is mediated by different combinations of CD4 transcriptional control elements functioning at different developmental stages. As the stem cell develops into a DN thymocyte, the silencer begins to function, thus inhibiting thymocyte enhancer function and CD4 expression. The thymocyte enhancer continues to function while the thymocyte undergoes positive and negative selection; should the DP thymocyte survive to complete this process, it will make a fate decision to become either a CD4 SP $\mathrm{T}_{\mathrm{H}}$ cell or a CD8 SP $T_{C}$ cell. Should the thymocyte become a CD4 SP $\mathrm{T}$ cell, it will initiate function of the $\mathrm{CD} 4 \mathrm{~T}$ cell enhancer only and thus continue to express CD4. However,

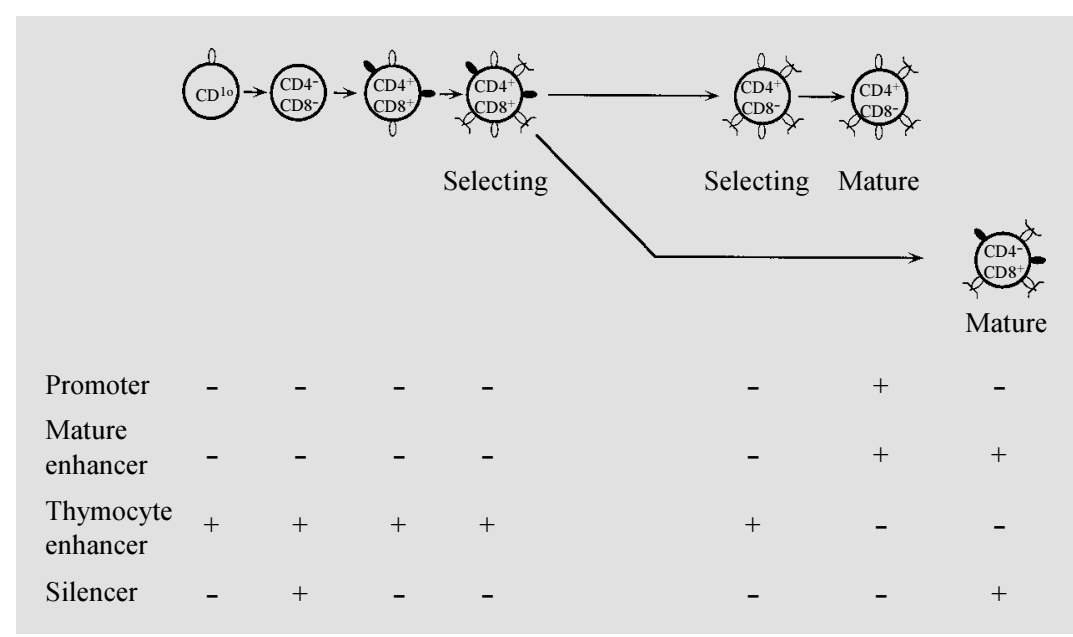

Figure 10 - Activity of the transcriptional control elements throughout T cell development. A timeline of T cell development is presented with the phenotypes of the cells indicated as in Figure 2. For each stage, the activity of each transcriptional element is indicated under it. Plus represents an active state and minus represents an inactive state, except for the promoter, where a minus represents a basal transcription activity. See text for details. 
should the thymocyte become a CD8 SP T cell it will initiate function of both the mature enhancer and the silencer, leading to the repression of CD4 expression. The work completed so far has therefore revealed a fascinating and complex machinery with only hints as to how it actually coordinates developmental CD4 gene expression; thus, the molecular immunologist is faced with a complex system that almost makes one nostalgic for the relative simplicity of Ptolemy's planetary orbital system.

In contrast, control of expression of genes important in early development is rarely simple. The bithorax complex of Drosophila is an excellent example of a complicated system of differentially regulated genes which are important in development (57). The homeotic proteins of Drosophila control the morphogenesis of position-specific features along the body axis during embryonic development. Their expression is restricted to dis- tinct domains along this axis throughout embryogenesis; ectopic expression of the genes that encode the homeotic proteins in inappropriate cells misdirects their development. The bithorax complex spans a large region of DNA, and contains at least three genes that encode for homeotic proteins: Ultrabithorax ( $U b x)$, abdominal-A ( $a b d-A)$, and Abdominal-B ( $A b d-B)$ (Figure 11). The $U b x$ gene is expressed in the middle region, whereas $A b d-B$ is expressed in the tail region of the body, indicating that the transcriptional control elements that determine the limits of these domains differ in their function. The control of transcription of these genes requires a complex set of different regulatory elements, including promoters, enhancers, silencers, and boundary elements. The CD4 gene expression control system has many similarities with the bithorax system. Like the $U b x$ gene, CD4 is expressed in early pluripotent precursors, its proper ex-

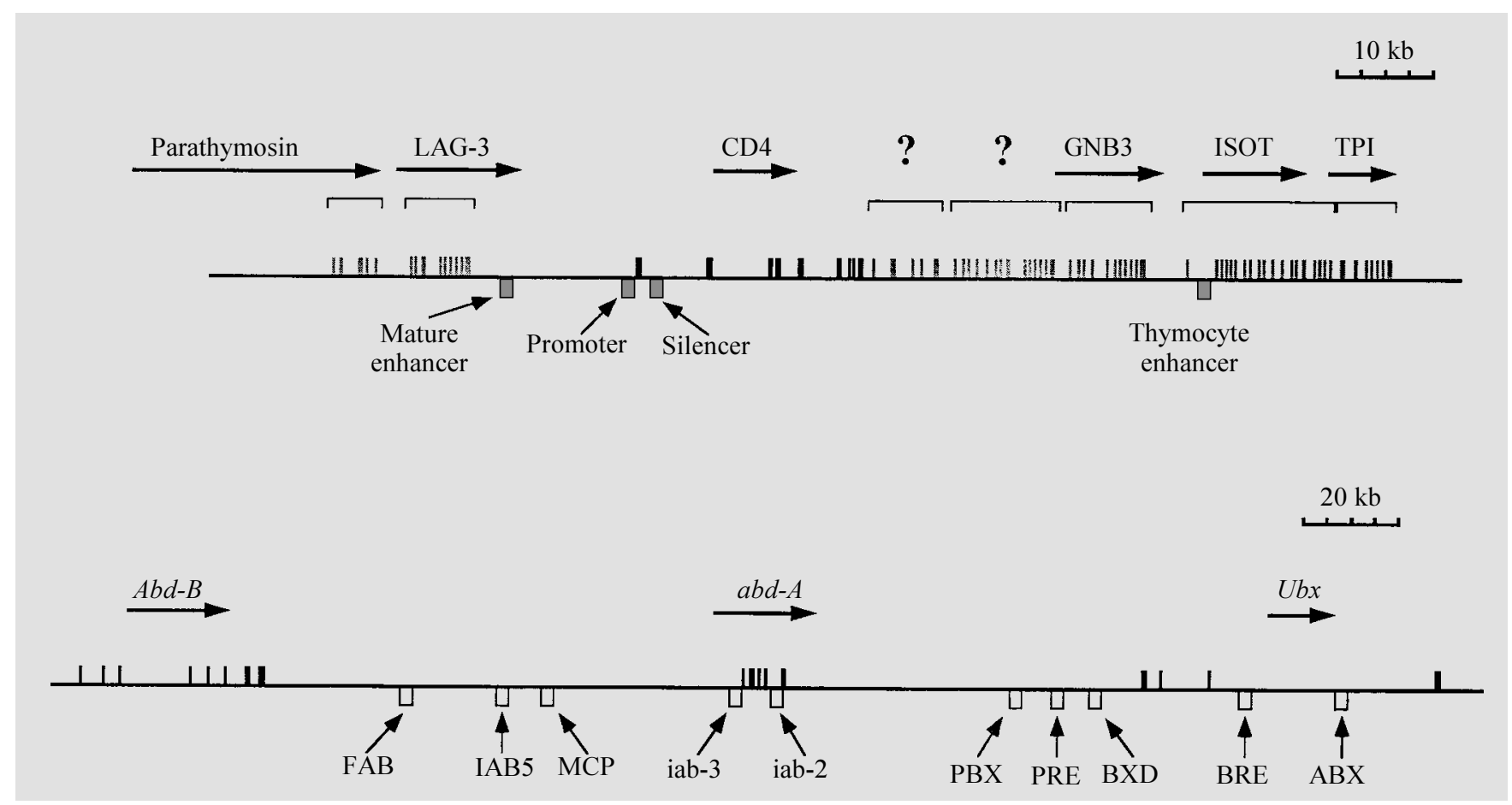

Figure 11 - Comparison between the organization of CD4 and bithorax gene loci. Exons are represented by vertical lines and control elements are represented by boxes. The genes are indicated above together with the direction of their transcription (horizontal arrows). The regulatory elements are indicated below with arrows pointing to the boxes for clarity. 
pression is required for appropriate cell development, and both the $U b x$ and CD4 loci have multiple transcriptional control elements that function at different stages of development (Figure 11). Thus the strategies for stage-specific expression control for these genes are very similar. The reasons for this are unknown, although it may be that if fine control of expression of a gene at different stages is required, it is more efficient to use multiple elements, each controlling expression at specific stages, as opposed to using one multifunctional element.

One important distinction of the CD4 locus is that the CD4 gene is found in a tight cluster of genes, none of which are as restricted in specificity of expression as CD4 $(39,58)$. The mature enhancer is located immediately 3 ' to the $L A G-3$ gene, whereas the thymocyte enhancer is located in the first intron of the isopeptidase $\mathrm{T}$ gene (Figure 11). Thus, the CD4 transcriptional control elements must in some manner be able to mediate transcription of CD4 and not the other genes in the locus. In this respect the CD4 gene is similar to the $\alpha$-globin gene cluster; the LCR that mediates cell typespecific $\alpha$ globin gene expression is located $40 \mathrm{~kb} 5^{\prime}$ from the promoter, in the intron of a constitutively expressed housekeeping gene (59). The mechanisms by which the CD4 elements interact specifically to mediate CD4 gene expression and ignore the other genes in the locus remain unclear.

\section{Future directions}

The original intent of the studies of CD4 gene expression was to investigate the connection between the signals that a T-cell receives through development to the decision to express or not to express the CD4 gene in the hope to identify both new regulatory elements and new signals in T-cell development. The work described in this review has revealed a very complex system at work with numerous control elements and redundant mechanisms. A lot has been revealed about the issues of regulatory elements and their trans-factors, while the associated signaling events have proven to be a greater challenge. The mechanism of silencing of the $\mathrm{CD} 4$ gene remains the central issue at hand. Further studies are necessary to address the issues of factor specificity as well as their connection to the signaling pathways. The next stage of investigation should also include strategies for understanding the functional hierarchy of the control elements.

\section{Acknowledgments}

We thank Dr. Richard Mann (Columbia University, New York) for helpful discussions and Matthew Adlam and Nika Danial (Columbia University, New York) for critical comments on the manuscript.

\section{References}

1. Fowlkes BJ \& Pardoll D (1989). Molecular and cellular events of T cell development. Advances in Immunology, 44: 207-264.

2. Wu L, Scollay $R$, Egerton $M$, Pearse $M$, Spangrude GJ \& Shortman K (1991). CD4 expressed on earliest $\mathrm{T}$-lineage precursor cells in the adult murine thymus. Nature, 349: 71-74.

3. von Boehmer H (1988). The developmental biology of T lymphocytes. Annual Review of Immunology, 6: 309-326.

4. Kruisbeek AM, Mond JJ, Fowlkes BJ,
Carmen J A, Bridges S \& Longo DL (1985). Absence of Lyt-2', L3T4+ lineage of T cells in mice treated neonatally with anti-la correlates with absence of intrathymic I-A bearing antigen-presenting cell function. J ournal of Experimental Medicine, 161: 1029-1047.

5. Berg LJ , Pullen AM, Groth BFDS, Mathis D, Benoist C \& Davis MM (1989). Antigen/MHC-specific T cells are preferentially exported from the thymus in the presence of their MHC ligand. Cell, 58:
1035-1046.

6. Cosgrove D, Gray D, Dierich A, Kaufman J, Lemeur $M$, Benoist $C \&$ Mathis $D$ (1991). Mice lacking MHC class II molecules. Cell, 66: 1051-1066.

7. Grusby MJ , J ohnson RS, Papaionnou VE \& Glimcher LH (1991). Depletion of CD4+ $\mathrm{T}$ cells in major histocompatibility complex class II-deficient mice. Science, 253: 1417-1420.

8. Perlmutter RM (1993). In vivo dissection of lymphocyte signaling pathways. Clini- 
cal Immunology and Immunopathology, 67: S44-S49.

9. Orr SL, Gese E \& Hood L (1992). A new approach to understanding $T$ cell development: the isolation and characterization of immature $\mathrm{CD}^{-}, \mathrm{CD} 8^{-}, \mathrm{CD}^{-}$cell cDNAs by subtraction cloning. Molecular Biology of the Cell, 3: 761-773.

10. Prendergast J A, Helgason CD \& Bleackley RC (1992). Quantitative polymerase chain reaction analysis of cytotoxic cell proteinase gene transcripts in T cells. Pattern of expression is dependent on the nature of the stimulus. J ournal of Biological Chemistry, 267: 5090-5095.

11. Kagi D, Vignaux F, Ledermann B, Burki K, Depraetere V, Nagata S, Hengartner H \& Golstein P (1994). Fas and perforin pathways as major mechanisms of T cell-mediated cytotoxicity. Science, 265: 528530.

12. Siu G, Wurster AL, Duncan DD, Soliman TM \& Hedrick SM (1994). A transcriptional silencer controls the developmental expression of the CD4 gene. EMBO J ournal, 13: 3570-3579.

13. Siu G, Wurster AL, Lipsick J S \& Hedrick SM (1992). Expression of the CD4 gene requires a Myb transcription factor. Molecular and Cellular Biology, 12: 15921604.

14. Salmon P, Giovane A, Wasylyk B \& Klatzmann D (1993). Characterization of the human CD4 gene promoter: Transcription from the CD4 gene core promoter is tissue-specific and is activated by Ets proteins. Proceedings of the National Academy of Sciences, USA, 90: 7739-7743.

15. Sawada S \& Littman DR (1991). Identification and characterization of a T-cell-specific enhancer adjacent to the murine CD4 gene. Molecular and Cellular Biology, 11: 5506-5515.

16. Wurster AL, Siu G, Leiden J \& Hedrick SM (1994). Elf-1 binds to a critical element in a second CD4 enhancer. M olecular and Cellular Biology, 14: 6452-6463.

17. Sands J F \& Nikolic-Zugic J (1992). T-cellspecific protein-DNA interactions occurring at the CD4 locus: identification of possible transcriptional control elements of the murine CD4 gene. International Immunology, 4: 1183-1194.

18. Sawada S, Scarborough J D, Killeen N \& Littman DR (1994). A lineage-specific transcriptional silencer regulates CD4 gene expression during $\mathrm{T}$ lymphocyte development. Cell, 77: 917-929.

19. Donda A, Schulz M, Burki K, De Libero G \& Uematsu Y (1996). Identification and characterization of a human CD4 silencer.
European J ournal of Immunology, 26: 493-500.

20. Hanna Z, Simard C, LaPerriere A \& J olicoeur $P$ (1994). Specific expression of the human $\mathrm{CD} 4$ gene in mature $\mathrm{CD}^{+}$ CD8- and immature $\mathrm{CD}^{+}{ }^{+} \mathrm{CD} 8^{+} \mathrm{T}$ cells and in macrophages of transgenic mice. Molecular and Cellular Biology, 14: 10841094.

21. Duncan DD, Stupakoff A, Hedrick SM, Marcu KB \& Siu G (1995). A Myc-associated zinc-finger protein (MAZ) binding site is one of four important functional regions in the CD4 promoter. Molecular and Cellular Biology, 15: 3179-3186.

22. Nakayama K, Yamamoto $R$, Ishii $S \&$ Nakauchi H (1993). Binding of c-Myb to the core sequence of the CD4 promoter. International Immunology, 5: 817-824.

23. Sarafova SD \& Siu G (1999). A potential role for Elf-1 in CD4 promoter function. J ournal of Biological Chemistry (in press).

24. Adlam M, Duncan DD, Ng DK \& Siu G (1997). Positive selection induces CD4 promoter and enhancer function. International Immunology, 9: 877-887.

25. Salmon P, Boyer O, Lores P, Jami J \& Klatzmann D (1996). Characterization of an intronless CD4 minigene expressed in mature CD4 and CD8 T cells, but not expressed in immature thymocytes. J ournal of Immunology, 156: 1873-1879.

26. Uematsu $Y$, Donda A \& De Libero G (1997). Thymocytes control the CD4 gene differently from mature $T$ lymphocytes. International Immunology, 9: 179-187.

27. Bendelac $A$, Matzinger $P$, Seder RA, Paul WE \& Schwartz RH (1992). Activation events during thymic selection. J oumal of Experimental Medicine, 175: 731-742.

28. Sawada S \& Littman DR (1993). A heterodimer of HEB and an E12-related protein interact with the CD4 enhancer and regulate its activity in T-cell lines. Molecular and Cell Biology, 13: 5620-5628.

29. Bain G, Engel I, Maandag EC, te Reile HPJ , Voland J R, Sharp LL, Chun J , Huey B, Pinkel D \& Murre C (1997). E2A deficiency leads to abnormalities in $\alpha ß$ T-cell development and to rapid development of T-cell lymphomas. M olecular and Cellular Biology, 17: 4782-4791.

30. Yan W, Young AZ, Soares VC, Kelley R, Benezra R \& Zhuang Y (1997). High incidence of T-cell tumors in E2A-null mice and $\mathrm{E} 2 \mathrm{~A} / \mathrm{Id} 1$ double-knockout mice. Molecular and Cellular Biology, 17: 73177327.

31. Duncan DD, Adlam M \& Siu G (1996). Asymmetric redundancy in CD4 silencer function. Immunity, 4: 301-311.
32. Kim HK \& Siu G (1998). The Notch pathway intermediate HES-1 silences CD4 gene expression. Molecular and Cellular Biology, 18: 7166-7175.

33. Robey E, Chang D, Itano A, Cado D, Alexander $\mathrm{H}$, Lane D, Weinmaster G \& Salmon P (1996). An activated form of Notch influences the choice between CD4 and CD8 T cell lineages. Cell, 87: 483-492.

33a. Allen RD, Bender TP \& Siu G (1999). cM yb is essential for early $T$ cell development. Genes and Development (in press).

34. Kim WWS \& Siu G (1999). Subclass-specific nuclear localization of a novel CD4 silencer binding factor. Molecular and Cellular Biology (in press).

35. Shore D (1995). Telomere position effects and transcriptional silencing in the yeast Saccharomyces cerevisiae. In: Blackburn $\mathrm{EH} \&$ Greider CW (Editors), Telomeres Plainview. Cold Spring Harbor Press, New York.

36. Lipsick JS (1996). One billion years of Myb. Oncogene, 13: 223-235.

37. Sasai $Y$, Kageyama $R$, Tagawa $Y$, Shigemoto R \& Nakanishi S (1992). Two mammalian helix-loop-helix factors structurally related to Drosophila hairy and enhancer of split. Genes and Development, 6: 2620-2634.

38. Ishibashi M, Ang SL, Shiota K, Nakanishi S, Kageyama R \& Guillemot F (1995). Targeted disruption of mammalian hairy and enhancer of split homolog-1 (HES-1) leads to up-regulation of neural helix-loop-helix factors, premature neurogenesis, and severe neural tube defects. Genes and Development, 9: 3136-3148.

39. Bruniquel $D$, Borie $N \&$ Triebel $F$ (1998). Genomic organization of the human LAG3/CD4 locus. Immunogenetics, 47: 96-98.

40. Hogquist KA, J ameson SC, Heath WR, Howard J L, Bevan MJ \& Carbone FR (1994). T cell receptor antagonist peptides induce positive selection. Cell, 76: 17-27.

41. Henderson AJ \& Calame KL (1995). Lessons in transcriptional regulation learned from studies on immunoglobulin genes. Critical Reviews in Eukaryotic Gene Expression, 5: 255-280.

42. J ohnson AD (1995). Molecular mechanisms of cell-type determination in budding yeast. Current Opinion Genetics and Development, 5: 552-558.

43. Komachi K, Redd MJ \& J ohnson AD (1994). The WD repeats of Tup1 interact with the homeo domain protein alpha 2. Genes and Development, 8: 2857-2867.

44. Bruhn L \& Sprague J r GF (1994). MCM 1 point mutants deficient in expression of 
alpha-specific genes: residues important for interaction with alpha 1 . Molecular and Cellular Biology, 14: 2534-2544.

45. Primig M, Winkler H \& Ammerer G (1991). The DNA binding and oligomerization domain of $M C M 1$ is sufficient for its interaction with other regulatory proteins. EMBO J ournal, 10: 4209-4218.

46. Kirkman-Correia C, Stroke IL \& Fields S (1993). Functional domains of the yeast STE12 protein, a pheromone-responsive transcriptional activator. Molecular and Cellular Biology, 13: 3765-3772.

47. Yuan YO, Stroke IL \& Fields S (1993). Coupling of cell identity to signal response in yeast: interaction between the alpha 1 and STE12 proteins. Genes and Development, 7: 1584-1597.

48. Vershon AK, J in Y \& J ohnson AD (1995). A homeo domain protein lacking specific side chains of helix 3 can still bind DNA and direct transcriptional repression. Genes and Development, 9: 182-192.

49. Mead J , Zhong H, Acton TB \& Vershon AK (1996). The yeast alpha2 and $\mathrm{Mcm} 1$ proteins interact through a region similar to a motif found in homeodomain proteins of higher eukaryotes. Molecular and Cellular Biology, 16: 2135-2143.

50. Zhong $H \&$ Vershon AK (1997). The yeast homeodomain protein MATalpha2 shows extended DNA binding specificity in complex with $\mathrm{Mcml}$. J ournal of Biological Chemistry, 272: 8402-8409.

51. Murre C, McCaw PS \& Baltimore D (1989). A new DNA binding and dimerization motif in immunoglobulin enhancer binding-daughterless, MyoD, and myc proteins. Cell, 56: 777-783.

52. Bossone SA, Asselin C, Patel AJ \& Marcu KB (1992). MAZ, a zinc finger, binds to a $c-m y c$ and $C 2$ gene sequences regulating transcriptional initiation and termination. Proceedings of the National Academy of Sciences, USA, 89: 7452-7456.

53. Bassuk AG \& Leiden J M (1997). The role of Ets transcription factors in the development and function of the mammalian immune system. Advances in Immunology, 64: 65-104.

54. Akazawa C, Sasai Y, Nakanishi S \& Kageyama R (1992). Molecular characterization of a rat negative regulator with a basic helix-loop-helix structure predomi- nantly expressed in the developing nervous system. J ournal of Biological Chemistry, 267: 21879-21885.

55. J acobson EM, Li P, Leon-del-Rio $A$, Rosenfeld MG \& Aggarwal AK (1997). Structure of Pit-1 POU domain bound to DNA as a dimer: unexpected arrangement and flexibility. Genes and Development, 11: 198-212.

56. Bronowski J (1973). The Ascent of Man. Little, Brown \& Company, Boston/ Toronto.

57. Bienz M \& MullerJ (1995). Transcriptional silencing of homeotic genes in Drosophila. Bioessays, 17: 775-784.

58. Ansari-Lari MA, Muzny DM, Lu J, Lu F, Lilley CE, Spanos S, Malley T \& Gibbs RA (1996). A gene-rich cluster between the CD4 and triosephosphate isomerase genes at human chromosome 12p13. Genome Research, 6: 314-326.

59. Vyas $P$, Vickers $M A$, Simmons $D L$, Ayyub H, Craddock CF \& Higgs DR (1992). Cisacting sequences regulating expression of the human alpha-globin cluster lie within constitutively open chromatin. Cell, 69: 781-793. 